\title{
Yellow fever stalks Brazil in Zika's wake
}

\author{
Owen Dyer
}

\section{Montreal}

Brazil has reported 921 suspected cases of yellow fever since December, the highest number in decades, prompting concerns of a major resurgence of this old enemy as health authorities see signs of a slow start to Brazil's second Zika season.

Yellow fever is a mosquito-borne flavivirus-a cousin to dengue, Zika, and West Nile virus. Once the scourge of the British Empire, it also devastated Napoleon's army in Egypt and killed hundreds of workers building the Panama Canal.

It remains deadly today, as 60 deaths have so far resulted from the 161 Brazilian cases in which yellow fever has been confirmed. A further 702 cases were still under investigation when the health ministry issued its last update on 3 February, but the number of cases continues to climb as new locations report outbreaks.

The geographical spread has Brazilian health authorities concerned. Most cases so far have come from Minas Gerais state, an area with a history of yellow fever and relatively high vaccination coverage in young people. The high average age of people infected-45-suggests an epidemic concentrated among older adults who grew up before mass vaccination campaigns.

Some $87 \%$ of confirmed Minas Gerais infections are in men, a normal finding with jungle yellow fever-namely, disease caught in or near the forest from mosquitoes that normally prey on primates.

Usually, the first sign of a jungle yellow fever epizootic is sudden silence from a forest normally raucous with monkey noises. Rumours of mass primate deaths are currently widespread around Brazil. Deforestation has divided the forests of Minas Gerais into more and smaller blocks, and more people than ever live close to them.

The last jungle yellow fever epidemic struck in 2007, though on a much smaller scale than this year's. All yellow fever in Brazil has been jungle yellow fever since the last outbreak of urban yellow fever in 1942 .

Yellow fever vaccine coverage is low in Brazil's big cities, and experts fear that the virus may take root in an urban mosquito population. A group of physicians and researchers warned in a letter to the health ministry that such urban transmission may already be occurring, but the country's experts are divided on the risk of urban yellow fever reappearing.

Cases have been reported in states adjoining Minas Gerais, including Bahia, São Paolo, and the previously unaffected Espírito Santo. Of seven confirmed yellow fever deaths in São Paolo state, five were traced to infections contracted in Minas Gerais; but two, in the municipalities of Batatais and Américo Brasiliense, were autochthonous cases. In the second case health authorities were unable to rule out urban transmission, which would make it Brazil's first death from urban yellow fever in 75 years.

Brazil's city residents have been lining up to be vaccinated, but health authorities currently recommend vaccination only in areas where jungle yellow fever is endemic. This policy is driven partly by a vaccine shortage and partly by fears of adverse vaccine reactions, which are rare but potentially serious.

Mark Boulos, virologist and São Paulo state's disease control coordinator, told the $O$ Globo newspaper, "In the epidemic that occurred seven years ago, in Botucatu, 11 people died, four of them due to the vaccine. Therefore, we do selective vaccination, when there is a concrete risk of acquiring the disease."

Brazil has already distributed 11.5 million vaccines and is ramping up production, but this is slow, and yellow fever experts fear for the second year running that global stockpiles are insufficient to cope with a worst case scenario.

In Africa, where yellow fever kills nearly 30000 people a year, a 2016 epidemic in Congo and Angola was tackled with fractionated vaccine doses at a fifth of normal strength, to spread out the available supply. ${ }^{1}$ Much of the vaccine provided came from emergency donations from South Sudan and Brazil.

Gulland A. Vigilance still needed to contain Africa's yellow fever outbreak, says WHO. BMJ 2016;354:i4756. doi:10.1136/bmj.i475627586155

Published by the BMJ Publishing Group Limited. For permission to use (where not already granted under a licence) please go to http://group.bmj.com/group/rights-licensing/ permissions 